\title{
PERAN SUAMI DALAM MERAWAT ANAK PADA WAKTU ISTRI MENYUSUI EKSLUSIF PALEMBANG TAHUN 2019
}

\author{
Devi cynthia Anggraini ${ }^{1}$, Rohani ${ }^{2}$ \\ 1.2 Prodi DIII Kebidanan STIKES Mitra Adiguna \\ Jl. Kenten Permai Blok J No 9-12 Bukit Sangkal Palembang \\ Email : ghinakiyasah@gmail.com
}

\begin{abstract}
Abstrak
Ayah atau suami memiliki peran yang sangat strategis dalam proses pemberian ASI, beberapa studi menunjukkan bahwa ayah berperan dalam mempengaruhi keputusan untuk menyusui, inisiasi praktek menyusui dan lamanya pemberian ASI. Penelitian ini bertujuan untuk mengetahui sejauh mana peran suami dalam merawat anak pada waktu istri menyusui ekslusif di wilayah kerja BPM Bismirawati Palembang. Desain penelitian menggunakan metode kualitatif dengan pendekatan fenomenologi, sampel penelitian ini 4 partisipan dan 1 informan kunci yang didapatkan menggunakan teknik wawancara mendalam. Dari wawancara yang dilakukan pada suami yang memberikan dukungan pada istri waktu menyusui sebagai partisipan dan Psikolog sebagai infroman kunci didapatkan informasi bahwa Tn"M" memberikan dukungan dengan cara membantu pekerjaan istri dan mengurus anak untuk keberhasilan istri dalam pemberian asi , Tn"A" memberikan dukungan dengan cara membantu mengurus anak pada waktu istri menyusui ekslusif untuk keberhasilan menyusui, Tn"S" memberikan dukungan pada istri untuk kelancaran menyusui dengan cara ikut serta mengurus anak dan Tn" $S$ " memberikan dukungan dengan cara membantu istri mengurus anak dan memperhatikan nutrisi istri waktu istri menyusui. Artinya bidan telah memberikan sosialisasi tentang pentingnya pemberian ASI dengan baik sehingga masyarakat mau memberikan ASI kepada anaknya sampai umur yang telah ditentukan. Diharapkan kepada tenaga kesehatan khususnya bidan lebih proaktif dalam melakukan penyuluhan kepada masyarakat tentang bagaimana pentingnya pemberian ASI pada bayi, karena ASI sangat banyak manfaatnya baik untuk ibu maupun untuk bayinya.
\end{abstract}

Kata Kunci $\quad$ :Peran Suami, Merawat anak, Menyusui Ekslusif

\begin{abstract}
Fathers or husbands have a very strategic role in the breastfeeding process, several studies show that fathers play a role in influencing the decision to breastfeed, initiate breastfeeding practices and the length of breastfeeding. This study aims to determine the extent of the role of husbands in caring for children when the wife is exclusively breastfeeding in the work area of BPM Bismirawati Palembang. The study design used a qualitative method with a phenomenological approach, the sample of this study was 4 participants and $1 \mathrm{key}$ informant obtained using in-depth interview techniques. From interviews conducted to husbands who gave support to wives when breastfeeding as participants and psychologists as key information, information was obtained that $M r$. " $M$ " provided support by helping wives work and taking care of their children for the wife's success in breastfeeding, Mr. "A" provided support by helping to take care of the child when the wife is breastfeeding exclusively for the success of breastfeeding, Mr. "S" gives support to the wife for smooth breastfeeding by participating in taking care of the child and "S" provides support by helping the wife take care of the child and pay attention to the wife's wife's nutrition breastfeeding. This means that the midwife has provided socialization about the importance of breastfeeding well so that people want to give milk to their children until the specified age. It is expected that health workers, especially midwives, will be more proactive in educating the public about the importance of breastfeeding babies, because breast milk has many benefits for both the mother and the baby.
\end{abstract}

Keywords : Role of Husband, Caring for children, Exclusive Breastfeeding 


\section{PENDAHULUAN}

Ayah atau suami memiliki peran yang sangat strategis dalam proses pemberian ASI, beberapa studi menunjukkan bahwa ayah berperan dalam mempengaruhi keputusan untuk menyusui, inisiasi praktek menyusui dan lamanya pemberian ASI, serta menjadi faktor risiko praktek pemberian susu formula. Ayah juga berperan dalam memberikan dukungan emosional pada ibu saat proses persalinan. Ayah juga diketahui ikut serta dalam proses pengambilan keputusan tentang pola pemberian makan bayi, terlibat dalam urusan perawatan anak, dalam pekerjaan rumah tangga, dalam ekonomi keluarga, serta berperan dalam menjaga keharmonisan hubungan rumah tangga (Judhiastuty, 2008).

Menurut Denise (2009), bayi memiliki begitu banyak kebutuhan. Perlu makan, perlu kontak fisik dengan manusia lain, perlu dibuat nyaman, perlu dijaga agar selalu kering dan bersih, dan perlu dikenalkan dengan dunia yang begitu besar, luas serta menakjubkan. "Ayah dapat berpartisipasi dalam semua kegiatan tersebut sambil melindungi kegiatan menyusui. Jika ayah mau menidurkan bayi, ayah tidak hanya member kesempatan ibu yang kelelahan menyusui dan merawat bayi seharian untuk beristirahat, melainkan menciptakan kebersamaan yang intim dengan bayi.

Ayah bisa mengajak bayi melihatlihat gambar di dinding, tanaman di halaman, atau diam-diam menikmati kebersamaan mereka. Menyaksikan ayah dan bayi tertidur bersama akan menimbulkan emosi positif dalam diri ibu menyusui, dan membantu meningkatkan hormon oksitosin (hormon yang mengalirkan ASI). Ibu menyusui akan merasakan emosi positif yang sama, jika ayah mau membacakan buku untuk bayi, mengajak bayi berjalan- jalan, mengobrol, memijat, dan masih banyak lagi (Utami, 2011). Ada kekuatan besar dalam tangan seorang pria dalam peran sebagai seorang ayah dan suami dalam keluarga. Berikut cara Ayah mambantu dalam proses menyusui: ayah menyendawakan bayi, memandikan bayi, bermain, bergurau dan mendendangkan bayi, mengganti popok, memijat bayi dan menggendong bayi.keluarga miskin yang mempunyai bayi kembar perempuan dan laki-laki, sehubungan dengan budaya patriakal ada kecenderungan untuk memberikan ASI bagi bayi laki-laki dan susu formula yang diencerkan bagi bayi perempuan, sehingga menyebabkan kematian bagi bayi tersebut.menyusui merupakan hadiah yang sangat berharga yang dapat diberikan orang tua pada bayinya dalam keadaan darurat dan miskin. ASI merupakan hadiah satusatunya yang dapat diberikan pada keadaan sakit dan darurat yang menyelamatkan jiwa bayi, jadi berikan bayi yang terbaik (Unicef \& WHO, 2006).

Menyusui adalah pekerjaan intensif waktu, dan wanita mungkin memerlukan berbagai jenis dukungan untuk inisiasi dan kelanjutan praktik menyusui yang optimal. Intinya pada saat menyusui, seseorang wanita perlu didengarkan. Sistem pendukung yang paling kritis adalah ayah bayi. Tinjauan literature juga mendukung bahwa di antara berbagai dukungan, "dukungan ayah" untuk menyusui adalah penting untuk mempromosikan praktik pemberian ASI ekslusif dan optimal (Yasmin, 2015).

Para ibu yang menerima dukungan dari pasangan mereka biasanya memilih untuk menyusui secara ekslusif dan optimal untuk bayi mereka, dan kemungkinan melanjutkan praktik ini lebih tinggi. Banyak penelitian juga mengungkapkan bahwa dukungan dari ayah sangat dihargai oleh para ibu (Yasmin, 2015). 
Dukungan ayah telah diidentifikasi sebagai salah satu prediktor terkuat ASI ekslusif dan optimal. Studi (Horton, 2005; Mitchell-Box \& Braun, 2012; Scott, Landers, Hughes, \& Binns, 2001) telah menegaskan bahwa ayah memainkan peran penting dalam mendukung menyusui. Littman, Medendrop, dan Goldfarb (1994) menganggap dukungan ayah penting dalam membantu ibu untuk memulai dan melanjutkan menyusui. Berbagai penelitian yang dilakukan di Amerika Serikat mengutip dukungan ayah sebagai kunci dalam memulai dan mempertahankan menyusui (Yasmin, 2015).

Dukungan dari ayah bayi melalui partisipan aktif dalam keputusan menyusui, bersama dengan sikap dan pengetahuan positif tentang manfaat menyusui, telah terbukti memiliki pengaruh kuat pada inisiasi dan durasi menyusui. Faktor yang paling signifikan untuk memulai pemberian susu botol adalah persepsi ibu tentang sikap ayah (Pisacan A, Continisio GI, Aldinucci M, D'Amora S, Continisio P Pediatrics 2005).

Berdasarkan survei pendahuluan yang peneliti lakukan diwilayah kerja BPM Bismirawati menunjukkan bahwa dukungan dari suami sangat berpengaruh untuk keberhasilan istri dalam memberikan ASI.

Berdasarkan uraian diatas penulis tertarik melakukan penelitian mengenai "peran suami dalam merawat anak pada waktu istri menyusui ekslusif"

\section{METODE PENELITIAN}

Penelitian ini menggunakan metode kualitatif dengan pendekatan fenomenologi. Dalam penelitian ini memfokuskan pada peran suami dalam merawat anak pada waktu istri menyusui ekslusif di wilayah kerja BPM Bismirawati Palembang, untuk mengetahui sejauh mana peran yang diberikan oleh suami dalam merawat anak pada waktu istri menyusui ekslusif. Menurut peneliti, pendekatan feneomenologi adalah cara yang dilakukan penelitian dalam mendekati informan untuk mengetahui pengalaman informan dalam mendukung pemberian ASI.

Peneliti ini direncanakan pada bulan Maret 2019 di wilayah kerja BPM Bismirawati Palembang. Peneliti ini meneliti tentang peran suami dalam merawat anak pada waktu istri menyusui ekslusif.

Sasaran dalam penelitian ini yaitu Suami yang memberikan peran dalam merawat anak pada waktu istri menyusui berupa dukungan informasi, penilaian, fisik dan emosional di wilayah kerja BPM Bismirawati Palembang.

\section{Data dan Cara Pengumpulannya}

Pada penelitian ini menggunakan data primer dan data sekunder yang didapat langsung dari informan/partisipan dengan cara mewawancarai secara mendalam.

Metode pengumpulan data dalam penelitian kualitatif diantaranya adalah wawancara, observasi/pengamatan, dokumentasi dan Fokus Group Discussion (FGD).

\section{Situasi Sosial dan Sampel Situasi Sosial}

Situasi sosial dalam penelitian ini adalah semua suami yang memberikan peran merawat anak pada waktu istri menyusui ekslusif sebagai partisipan dan seorang psikolog sebagai partisipan kunci.

\section{Sampel}

Penelitian ini menggunakan 4 orang suami sebagai partisipan yang telah memberikan peran dalam merawat anak pada waktu istri menyusui untuk memberikan ASI Ekslusif selama 6 bulan dan 1 orang Psikolog sebagai informan kunci.

Sampel pada penelitian ini diambil dengan menggunakan purpose sampling dengan berbagai pendekatan yang paling refresentatif untuk penelitian kualitatif. 


\section{HASIL PENELITIAN DAN PEMBAHASAN}

Dari wawancara yang dilakukan pada suami yang memberikan dukungan pada istri waktu menyusui sebagai partisipan dan Psikolog sebagai infroman kunci didapatkan informasi bahwa Tn"M" mengetahui pentingnya dukungan dari suami untuk keberhasilan dalam pemberian asi dan sudah memberikan dukungan pada istri untuk keberhasilan menyusui , Tn"A" sudah mengerti bahwa dukungan dari seorang suami berpengaruh dalam kelancaran pemberian asi dan sudah memberikan dukungan pada istri untuk keberhasilan menyusui , Tn"S" sudah memberikan dukungan pada istri untuk kelancaran menyusuim dan Tn"S" sudah paham bahwa dukungan dari seorang suami berpegaruh besar untuk keberhasilan istri dalam pemberian asi. Artinya bidan telah memberikan sosialisasi tentang pentingnya pemberian ASI dengan baik sehingga masyarakat mau memberikan ASI kepada anaknya sampai umur yang telah ditentukan.

Tn"B" sebagai partisipan kunci menjelaskan peran suami sangat diharapkan meskipun tidak banyak memberikan bantuan. Namun motivasi dan dukungan pada istri yang sedang menyusui sangat diharapkan karena secara psikologis dengan memberikan perhatian dan ikatan pada bayi dan suami tetap menvari informasi tentang proses menyusui berpengaruh untuk keberhasilan menyusui.

Dukungan suami adalah dukungan yang diberikan suami terhadap istri, suatu bentuk dukungan dimana suami dapat memberikan bantuan secara psikologis baik berupa motivasi, perhatian dan penerimaan. Dukungan suami merupakan hubungan bersifat menolong yang mempunyai nilai khusus bagi istri sebagai tanda adanya ikatan-ikatan yang bersifat positif (Goldberger \& Breznis, 1982).

Secara psikologis, seseorang ibu yang didukung suami atau keluarga akan lebih termotivasi, salah satunya dalam hal memberikan ASI ekslusif kepada bayinya (Prasetyono dalam Sari, 2011). Februhartanty (2008) mengungkapkan bahwa untuk memenuhi ASI ekslusif diperlukan adanya keharmonisan hubungan pola menyusui tripartif, yaitu antara ayah, ibu, dan bayi.

Keberhasilan menyusui sangat ditentukan oleh peran suami karena suami akan turut menetukan kelancaran refleks pengeluaran ASI (let down reflex) yang sangat dipengaruhi oleh keadaan emosi atau perasaan ibu. Suami dapat berperan aktif dengan memberikan dukungan-dukungan emosional dan bantuan-bantuan praktis lainnya, seperti mengganti popok, menyendawakan bayi, menggendong dan menenangkan bayi yang gelisah, memandikan bayi, memberikan ASI perah, membawa bayi jalan-jalan di taman dan memijat bayi. Pengertian tentang perannya yang penting ini merupakan langkah pertama bagi seorang suami mendukung ibu agar berhasil menyusui secara eksusif (Roesli, 2009).

Peningkatan keterlibatan suami merupakan strategi untuk memotivasi pemberian ASI ekslusif, karena keputusan memberikan ASI ekslusif bukan hanya ditentukan oleh ibu. Kebanyakan ibu hamil dan ibu menyusui yang telah mendapatkan penyuluhan tentang ASI tidak mempraktekkan pengetahuan yang didapatnya karena mereka bukan pengambil keputusan yang utama dalam keluarga untuk memberikan ASI ekslusif (Widodo, 2001 dalam Ferawati, 2010).

Berdasarkan hasil wawancara mendalam saya melihat suami ini benarbenar memberikan dukungan pada istri waktu menyusui dengan cara memberikan motivasi dalam bentuk bantuan-bantuan praktis untuk meringankan pekerjaan istri, memenuhi nutrisi istri, membantu mencari informasi tentang asi, mengingatkan istri untuk memberikan asi pada bayi dan ikut memantau perkembangan bayi. 
Berdasarkan pengetahuan mereka, para suami sudah mengerti jika dukungan dari suami berpengaruh untuk keberhasilan istri dalam memberikan asi. Artinya dukungan suami pada istri waktu menyusui sangat berpengaruh untuk keberhasilan istri dalm memberikan ASI. Hal tersebut sesuai dengan teori Menurut Roesli (2018) dalam Wahyuningsih (2012), dari semua dukungan bagi ibu menyusui dukungan suami adalah dukungan yang paling berarti bagi ibu. Suami dapat berperan aktif dalam keberhasilan pemberian ASI khususnya ASI ekslusif dengan cara memberikan dukungan secara emosional dan bantuanbantuan yang praktis. Untuk membesarkan seorang bayi, masih banyak yang dibutuhkan selain menyusui seperti menyendawakan bayi, menggendong dan menenangkan bayi yang gelisah, mengganti popok, memandikan bayi, membawa bayi jalan-jalan di taman, memberikan ASI perah, dan memijat bayi. Kecuali menyusui semua tugas tadi dapat dikerjakan oleh ayah. Menurut Djamaludin \& Eveline, 2010 Dukungan suami melalui breastfeeding father sangat membantu kelancaran ASI. Breastfeeding father merupakan peran dan keterlibatan aktif suami memberi dukungan moral dan emosional dalam pemberian ASI. Perhatian dan limpahan kasih sayang suami kepada ibu dan bayi. Suami turut menemani saat ibu bangun malam untuk menyusui, mengganti popok, atau mengambilkan minum, mengambilkan makanan setelah menyusui, hal tersebut akan mendorong refleks kimiawi tubuh untuk memproduksi ASI.

\section{KESIMPULAN}

a. Berdasarkan 4 Partisipan mengatakan bahwa dengan memberikan bantuanbantuan praktis pada istri yang sedang menyusui, mengingatkan untuk meberikan asi, memotivasi dan ikut mengurus bayi dapat meringankan beban istri dan membuat istri lebih semangat untuk memberikan asi pada bayi .

b. Berdasarkan Psikolog "B" mengatakan bahwa dukungan suami sangat berpengaruh dengan optimisme seorang ibu menyusui. Kehadiran seorang suami berperan penting bagi ibu yang sedang menyusui unyuk bertukar fikiran, mendapat motivasi dan dukungan dalam pemberian asi dan dapat membantu menyelesaikan masalah yang sedang dihadapai. Dukungan yang dapat dilakukan suami pada istri waktu menyusui dapat berupa menemani istri saat sedang menyusui, mencari informasi tentang asi, memberikan perhatian dan ikatan pada bayi dan memberikan bantuan-bantuan praktis walaupun tidak banyak.

\section{SARAN}

Diharapkan kepada peneliti selanjutnya untuk dapat melanjutkan penelitian studi kasus ini dengan melibatkan partisipan yang lebih banyak dan waktu penelitian yang lebih lama serta lokasi yang berbeda sehingga hasil penelitian yang didapatkan semakin baik.

\section{DAFTAR PUSTAKA}

Denise, 2009, Partisipasi Ayah dalam Peningkatan ASI Ekslusif. Jakarta

Februhartanty, J. 2009. ASI, dari ayah untuk ibu dan bayi. Semesta Media.

Judhiastuty, 2008. Strategic roles of fathers in optimizing breastfeeding practices: a study in an urban setting of Jakarta, Summary of the dissertation, University of Indonesia

Khasanah, Nur. 2011. ASI atau Formula. Jakarta: flash book. 
Pemprov DKI Jakarta. 2010. Pemberian

ASI ekslusif perlu ditingkatkan

(Diakses 19 november 2011).

Ramadani, M., Hadi, E.H. 2010. Dukungan suami dalam pemberian asi ekslusif di wilayah kerja puskesmas air tawar kota Padang, Sumatra Barat. Jurnal kesehatan masyarakat Nasional, 4(6), 269274.

Handayani, Riska Ayu.2018. Motivasi suami mendukung pemberian asi ekslusif di wilayah kerja puskesmas kecamatan ciawi kabupaten bogor 2017. Jakarta: Universitas Islam Negeri.

Roesli, U., 2009. Panduan Praktis menyusui. Jakarta: Puspaswara.

Theresa Hunter ${ }^{1}$, Georg'ann Cattelona ${ }^{2}$. Breastfeeding initiation and duration in first-time mothers: exploring the impact of father involvement in the early postpartum period. Health promotion perspectives, 2014, 4(2), 132-136. doi:10.5681/hpp.2014.017

http://journals.tbzmed.ac.ir/HPP .

Utami, 2011, Sehat dan Produktif berkat Menyusui" Breastfeeding Fair, Jakarta

Yasmin Mithani, RM, RN, BScN,IBCLC,MSc, Zahra Shaheen Premani, RN, BScN, IBCLC, MSc, Zohra Kurji, RN, BScN, IBCLC, MSc, Shehnaz Rashid, RN, BScN, IBCLC,MPH. Exploring father's role in breastfeeding practices in the urban and semiurban settings of karachi, Pakistan. The journal of perinatal education Fall 2015, Volume 24, Number 4. 